\title{
Energetic Analysis of the Aircraft Diesel Engine
}

\author{
Łukasz Grabowski ${ }^{1, *}$, Konrad Pietrykowski ${ }^{1}$, and Paweł Karpiński ${ }^{1}$ \\ ${ }^{1}$ Lublin University of Technology, Faculty of Mechanical Engineering, Department of Thermodynamics, Fluid Mechanics and \\ Aviation Propulsion Systems, Nadbystrzycka 36 Str., 20-618 Lublin, Poland
}

\begin{abstract}
The analysis of the distribution of thermal energy generated during the combustion process in internal combustion engines and the estimation of individual losses are important regarding performance and efficiency. The article analyses the energy balance of the designed two-stroke opposed piston diesel engines with offset, i.e. the angle by which the crankshaft at the side of exhaust ports is ahead of the crankshaft at the side of intake ports. Based on the developed zero-dimensional engine model, a series of simulations were performed in steady-state conditions using the AVL BOOST software. The values of individual energy losses, including cooling losses, exhaust gas losses, friction losses were obtained. The influence of decreasing and increasing the offset on the performance of the tested engine was analysed.
\end{abstract}

\section{Introduction}

In aviation, both turbine and piston engines are used. The choice of the drive depends on the assumptions for the design of a particular aircraft. There is no doubt that in the case of aircrafts that travel at relatively low speeds, it is reasonable to choose piston engines. Such a solution results directly from flight time which affects the mass balance of the implemented drive and fuel. The mass of the turbine engine unit, including the fuel, is significantly lower than the weight of the piston engine unit only on short flights $[1,2]$. If there is no need to move at high speeds, the reciprocating drive in airplanes meets those expectations. For this reason, a testing of internal combustion piston engines continues. In the paper [3], the analysis of the air exhaust components of the ASz62-IR piston was performed during the test flight, while in [4] the authors dealt with the design of the Rotax $912 \mathrm{~S}$ air cooling system. In a study described in [5], a Wankel engine supplied by synthetic fuels was considered for the use in aircrafts. There is a different distribution of thermal energy generated during the combustion process in particular cylinders as a result of the construction of the radial engine. Authors showed combustion variability and uniqueness in the 9-cylinder radial engine ASz62-IR [6]. Among the piston engines, two-stroke engines which are characterised by higher thermal efficiency compared to four-stroke engines deserve particular attention. In addition, they provide more unit power and their construction is simple due to no timing system. Compared to four-stroke engines, they are characterised by low losses of heat to the coolant, while at the same time they have higher heat losses [7].

The body of literature devoted to the energy analysis of two-stroke diesel engines is scant. Analyses of the distribution of thermal energy generated in the fuel combustion process and the estimation of heat losses are particularly important for performance and efficiency. One of the forms of energy flow presentation in an internal combustion engine is the Sankey diagram, in which individual thermal losses are presented as arrows or blocks with a width proportional to the size of these losses [8].

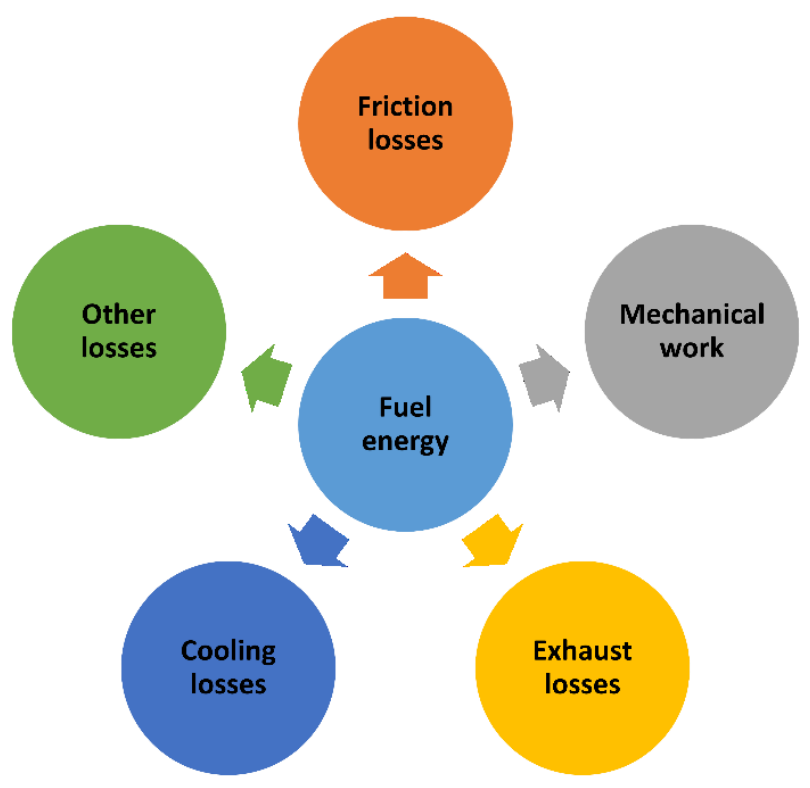

Fig. 1. Diagram of energy distribution in an internal combustion engine.

In general, the thermal balance of the engine is based on the measurement of mechanical energy and thermal energy that the engine transfers to the outside. It is possible to present an extended balance taking into account the distribution of energy inside the cylinder. An example of the balance equation is given by (1):

${ }^{*}$ Corresponding author: 1.grabowski@pollub.pl 


$$
N=N_{e}+N_{o}+N_{c}+N_{f}+N_{r}
$$

where: $N$ - heat supplied to the engine in the form of chemical energy contained in the fuel, $N_{e}$ - useful heat $(24 \div 40 \%), N_{o}$ - exhaust losses $(27 \div 38 \%), N_{c}$ - cooling losses $(26 \div 32 \%), N_{f}$ - friction losses $(7 \div 10 \%), N_{r}-$ rest of the energy.

The approximate ranges of individual losses for spark-ignition engines are given in brackets. In practice, these values strongly depend on the design of the engine.

In addition to usable energy which is used to drive the crankshaft and external receivers, a significant share in the engine energy balance is heat transmitted to exhaust gases and heat received by the cooling system. Both represent approx. 1/3 of the total energy supplied to the engine. Another factor responsible for significant energy losses (about 1/10 of supplied energy) is the friction occurring in the crank-piston system. The publication [9] analyses the change in the thermal balance of a diesel engine depending on its load, accounting for the number of individual losses. The paper [10] presents the energy balance and performance of a supercharged SI engine fuelled with natural gas. The use of supercharging and the change of fuel from gasoline to natural gas have resulted in an increase in thermal efficiency by several per cent. In addition, it was found that the increase in the load results in a percentage reduction in thermal losses to the coolant. The paper [11] presents the analysis of heat balance for two supercharged diesel engines and one naturally aspirated diesel engine. It was determined how much of the energy supplied in the fuel is converted into useful work, the heat contained in the exhaust gases and the heat transferred to the walls.

Piston crowns, piston rings and a cylinder liner in two-stroke engines show a significant thermal load due to high turbulence and no stroke in which cooling would take place, as it is in four-stroke engines. This results in the need for intensive cooling of these elements or the use of technological solutions that increase their strength. An example of the latter is the use of special TBC coatings, capable of reducing heat transfer from the inside of the combustion chamber to the walls of the cylinder and head. The tests performed in [12] have shown that the use of this type of coating in a diesel engine reduces by a dozen or so percent the amount of heat discharged to the coolant compared to a standard engine running at full load. At the same time, the heat loss associated with the exhaust is increased by more than $20 \%$. The use of TBC coating slightly increases the overall efficiency (brake thermal efficiency) $[13,14]$ and improves the performance [15]. The paper [16] presents the effect of using ceramic coatings on the energy balance of a diesel engine.

The development of the construction of internal combustion engines based on the Otto or Diesel cycle is limited due to the fact that their efficiency limit has been reached. Therefore, in order to improve their performance, it is important to focus on the analysis of losses and the attempt to minimise them.

The simplest form of recovering a part of lost heat in the engine is the use of a turbocharger capable of increasing engine power. An example is the work [17] which presents some tests of a diesel engine with an asymmetric twin-scroll turbine.

One of the forms of reducing heat loss, or actually recovering a part of lost heat in internal combustion engines, is the use of the Rankine cycle or Organic Rankine cycle (ORC). The paper [18] presents the general characteristics of this method with particular attention to the types of fluids that can be used in this cycle. The authors of the work also focused on the characteristics of fluids [19]. The work [20] shows that the use of this method results in a more than a dozen percent increase in thermal efficiency. The authors of the work [21] proposed different configurations of the exhaust gas energy recovery system based on the organic Rankine cycle.

Changing the type of fuel in the engine may result in a reduction of heat losses, as shown in the work [22], where the use of hydrogen instead of gasoline reduced heat loss to the cooling fluid with unchanged exhaust heat loss. In addition, efficiency can be improved by adding an additional fluid to the combustion chamber. This type of research was performed in the work [23] where the injection of water into the SI engine powered by LPG and the effect of this process on thermal losses were analysed. The effect of adding gasoline to diesel oil on the performance and efficiency of the diesel engine was examined in [24], while the heat balance of an engine powered with diesel oil was compared with that of an engine powered by a mixture of ethanol and diesel oil in [25].

The efficiency of the diesel engine with a varying intensity of turbulence inside the cylinder was also investigated [26]. The research presented in this paper shows that turbulence in the cylinder has a small effect on indicated efficiency.

It is also possible to recover a part of lost heat energy and convert it to electricity using low- $[27,28]$ and highpower [29] thermo-generators.

The purpose of this work is to analyse the distribution of energy released in the fuel combustion process depending on the offset occurring between crankshafts in a two-stroke diesel engine with an antiroll cylinder system. The research works aimed to examine what part of the power produced by the engine is taken by the compressor, what energy losses occur due to friction and as a result of heat escape to engine block elements. Finally, a Sankey chart was presented showing the energy distribution for a single work cycle of the created engine model.

\section{Engine model}

A zero-dimensional engine model was developed in the AVL BOOST software (Fig. 2). It is based on the first law of thermodynamics, and the time variable is independent. In addition, the method of spreading the flame is not included there. The mass burning rate is preset. A map of the Rotrex C30-64 compressor from the manufacturer was imported to the model. In order to improve the filling process behind the compressor, an air 
intercooler model was created. The basic engine parameters are presented in Table 1.

Table 1. Basic technical parameters of the tested engine.

\begin{tabular}{|l|l|}
\hline Engine type & $\begin{array}{l}\text { Two-stroke opposed-piston diesel } \\
\text { engine }\end{array}$ \\
\hline Type of scavenging & $\begin{array}{l}\text { Uniflow performed by a mechanical } \\
\text { compressor with an intercooler }\end{array}$ \\
\hline Number of cylinders & 3 \\
\hline Bore & $65.5 \mathrm{~mm}$ \\
\hline Stroke & $72 \mathrm{~mm}$ \\
\hline Compression ratio & $22: 1$ \\
\hline Take-off power & $100 \mathrm{~kW}$ \\
\hline Offset & $14^{\circ}$ \\
\hline
\end{tabular}

The combustion process was defined by the Viebe function. This function is characterised by the rate of heat release in the crank angle function and depends on the following variables: start of combustion $\mathrm{SoC}$, combustion duration $C D$, curve parameter $m$ and parameter $a$, depending on how much of the fuel injected will be burnt. [30] The following parameters of the Viebe function were adopted in the model of the tested engine:

- start of combustion $\mathrm{SoC}=-0.7^{\circ}$,

- combustion duration $C D=40^{\circ}$,

- curve parameter $m=0.7$,

- parameter $a=6.9$.

The heat exchange through the cylinder walls was defined using the standard Woschni 1978 model. For this purpose, the piston and cylinder surface areas and the temperatures on their surfaces were introduced to the engine model. In addition, the swirl ratio $S R=1.5$ was defined to account for the influence of turbulence of the charge on the heat exchange coefficient $h$.

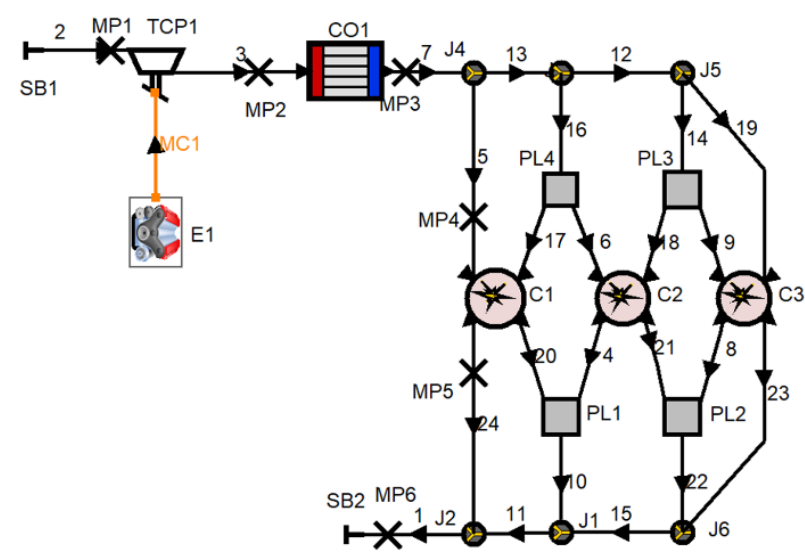

Fig. 2. The engine model created in the AVL BOOST software.

The pistons in opposed-cylinder engines do not move absolutely concurrently to improve the filling of cylinders with a fresh charge. The crankshaft at the side of outlet ports is ahead of the crankshaft at the side of intake ports by a certain angle called the offset. As a result of the earlier closing of outlet ports, the charging process is more effective. The offset for the tested engine is shown in Fig. 3.

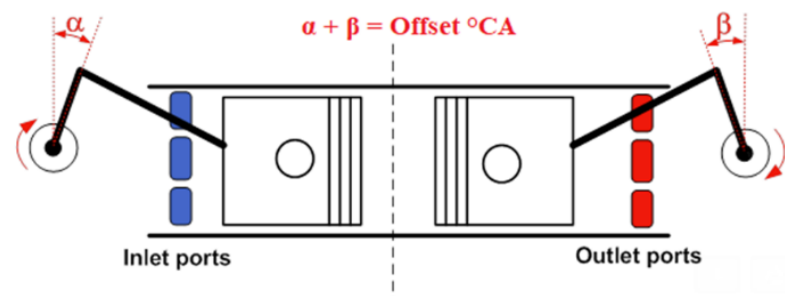

Fig. 3. Offset as a difference in the piston phases.

In this work, individual energy losses were analysed depending on the assumed offset value. For this purpose, three variants of the engine model were developed, achieving the same power but differing in the offset which was $10^{\circ}, 14^{\circ}$ and $20^{\circ}$. The same power for the analysed cases was obtained by changing the gear ratio between the crankshaft and the compressor shaft in the Model Parameters module and by changing the characteristics of the inlet and outlet ports in the cylinder settings. The tests were performed for fixed engine operating conditions for a maximum continuous power of $86 \mathrm{~kW}$ at $4000 \mathrm{rpm}$. Assumed $A F R$ equal to 24.5 and the start of combustion $S o C$ equal to $-0.7^{\circ}$, Table 2 presents computational cases defined in the Case Explorer module.

Table 2. Computational cases defined in the AVL BOOST software.

\begin{tabular}{|c|c|c|c|}
\hline $\begin{array}{c}\text { Case } \\
\text { number }\end{array}$ & Power & $\begin{array}{c}\text { Offset } \boldsymbol{O} \\
\left({ }^{\circ}\right)\end{array}$ & $\begin{array}{c}\text { Gear ratio } \\
(-)\end{array}$ \\
\hline 1 & \multirow{2}{*}{\begin{tabular}{c} 
Maximum \\
continuous power, \\
\cline { 3 - 4 }
\end{tabular}} & 10 & $24.583: 1$ \\
\cline { 3 - 4 } & $86 \mathrm{~kW}$ & 14 & $21.365: 1$ \\
\hline 3 & & 20 & $21.034: 1$ \\
\hline
\end{tabular}

\begin{tabular}{|c|c|c|c|}
\hline $\begin{array}{c}\text { Case } \\
\text { number }\end{array}$ & $\begin{array}{l}\text { Engine speed } \\
n(\mathrm{rpm})\end{array}$ & $\begin{array}{l}\text { Height of the } \\
\text { inlet ports } \\
(\mathrm{mm})\end{array}$ & $\begin{array}{l}\text { Height of the } \\
\text { exhaust ports } \\
\text { (mm) }\end{array}$ \\
\hline 1 & \multirow{3}{*}{4000} & \multirow{3}{*}{10} & 13 \\
\hline 2 & & & 13 \\
\hline 3 & & & 15 \\
\hline
\end{tabular}

\section{Results and discussion}

The simulation enabled us to establish the power generated as a result of fuel combustion in one of the cylinders of the engine under test for the defined calculation cases. In addition, the value of effective power on the crankshaft and the power values of particular losses occurring during the engine operation such as: power necessary to drive the compressor, power friction losses, power lost in exhaust gases, power lost in the cooling fluid, power lost in the intercooler. The balance up to $100 \%$ supplements the other losses including those of blow-by, radiation and heat transfer through the connecting pipes. The values of individual 
losses for the defined calculation cases are presented in Table 3 .

Table 3. Calculated energy for different offset values for the continuous maximum power.

\begin{tabular}{|c|c|c|c|}
\hline Type of energy & $\boldsymbol{O}=\mathbf{1 0}^{\circ}$ & $\boldsymbol{O}=\mathbf{1 4}^{\circ}$ & $\boldsymbol{O}=\mathbf{2 0}^{\circ}$ \\
\hline Fuel power $(\mathrm{kW})$ & 237.8 & 222.5 & 223.8 \\
\hline $\begin{array}{c}\text { Fuel power + cylinder } \\
\text { power }(\mathrm{kW})\end{array}$ & 245.7 & 227.4 & 228.6 \\
\hline Effective power $(\mathrm{kW})$ & 85.9 & 85.4 & 85.7 \\
\hline Compressor power $(\mathrm{kW})$ & 18.7 & 11.6 & 11.5 \\
\hline Intercooler power $(\mathrm{kW})$ & 10.9 & 6.8 & 6.7 \\
\hline Cylinder power $(\mathrm{kW})$ & 7.8 & 4.8 & 4.8 \\
\hline Friction losses $(\mathrm{kW})$ & 16.6 & 15.9 & 15.9 \\
\hline Exhaust losses $(\mathrm{kW})$ & 89.8 & 84.0 & 85.6 \\
\hline Cooling losses $(\mathrm{kW})$ & 28.6 & 27.0 & 26.3 \\
\hline Other losses $(\mathrm{kW})$ & 6.1 & 3.5 & 3.6 \\
\hline
\end{tabular}

Fig. 4 shows the percentage change in the calculated powers depending on the offset in relation to the reference value equal to $O=14^{\circ}$.

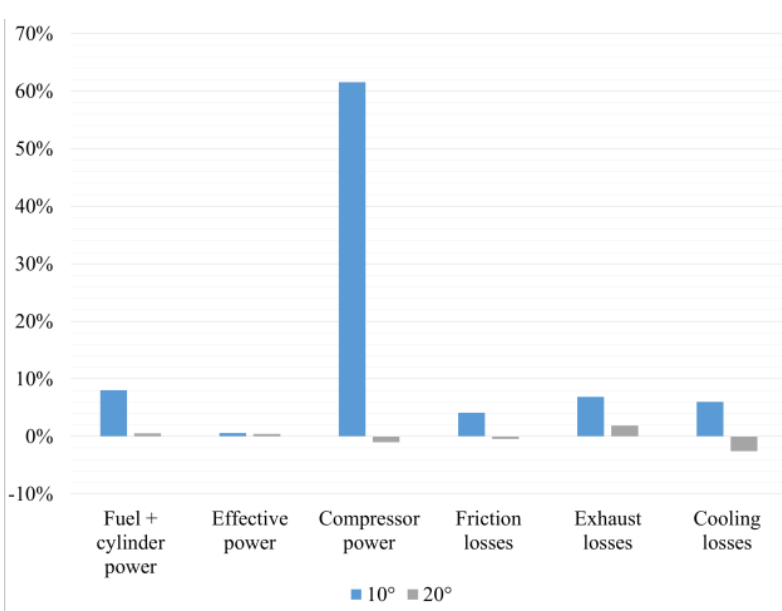

Fig. 4. Percentage change of the calculated powers for different offset values for the continuous maximum power.

The friction, exhaust and cooling losses for the offset of $10^{\circ}$ increased respectively by $4.1 \%, 6.9 \%$ and $6.0 \%$ to the reference offset value. The power consumed by the compressor increased by more than $60 \%$. This increase is due to the change in the gear ratio between the crankshaft and the compressor. The power delivered to the cylinder increased by $8 \%$, which results from the necessity of delivering more fuel in order to maintain the effective power at a constant level in accordance with the research assumptions. The increase in the offset value to $20^{\circ}$ results in a nearly $2 \%$ increase in outflow losses and a $2.6 \%$ decrease in cooling losses. The power consumed by the compressor dropped by $1 \%$ and the friction losses decreased by $0.5 \%$. The amount of energy supplied per unit of time has not changed significantly compared to the reference case.

On the basis of the determined power values, the percentage shares of particular losses were calculated in relation to the total amount of energy released as a result of fuel combustion during a single engine operation cycle. These shares are shown in Table 4, and for the reference offset in Fig. 5.

Table 4. Percentage shares of the calculated power for different offset values for the continuous maximum power.

\begin{tabular}{|c|c|c|c|}
\hline Type of energy & $\boldsymbol{O}=\mathbf{1 0}^{\circ}$ & $\boldsymbol{O}=\mathbf{1 4}^{\circ}$ & $\boldsymbol{O}=\mathbf{2 0}^{\circ}$ \\
\hline $\begin{array}{c}\text { Fuel power + cylinder } \\
\text { power (kW) }\end{array}$ & $100 \%$ & $100 \%$ & $100 \%$ \\
\hline Effective power (kW) & $35.0 \%$ & $37.5 \%$ & $37.5 \%$ \\
\hline Compressor power (kW) & $7.6 \%$ & $5.1 \%$ & $5.0 \%$ \\
\hline Friction losses (kW) & $6.8 \%$ & $7.0 \%$ & $6.9 \%$ \\
\hline Exhaust losses (kW) & $36.6 \%$ & $37.0 \%$ & $37.5 \%$ \\
\hline Cooling loses $(\mathrm{kW})$ & $11.6 \%$ & $11.9 \%$ & $11.5 \%$ \\
\hline Other losses $(\mathrm{kW})$ & $2.5 \%$ & $1.5 \%$ & $1.6 \%$ \\
\hline
\end{tabular}

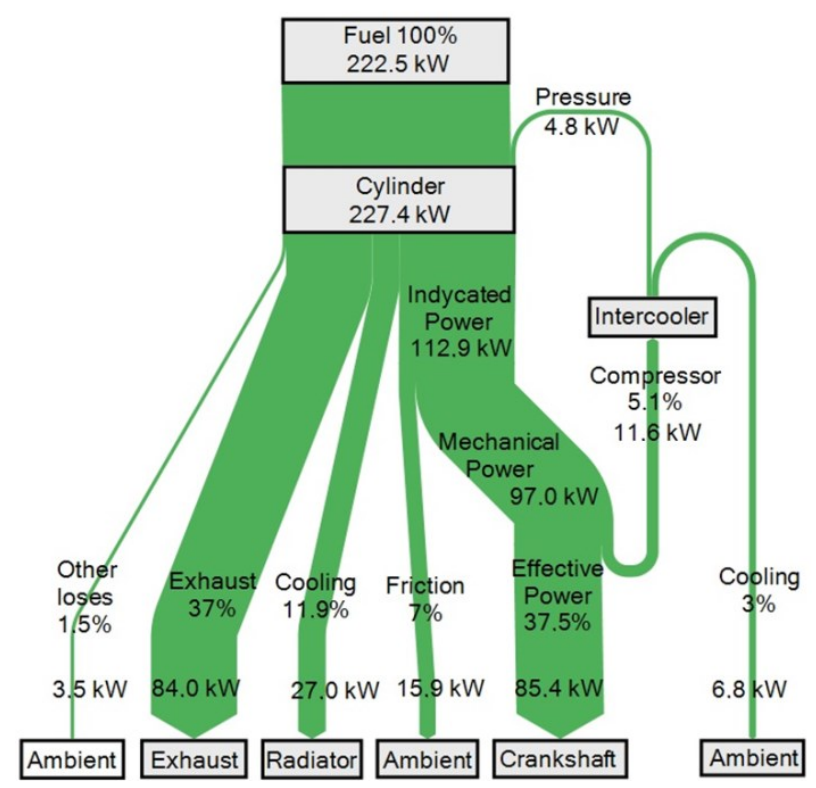

Fig. 5. Sankey diagram showing the energy balance of the tested engine for the offset of $14^{\circ}$.

Fig. 6 shows the percentage shares of the calculated power for different offset values for the continuous maximum power. Regardless of the offset value, the effective power and the power of the exhaust losses are the largest percentage shares. The share of the power of the exhaust losses slightly increases with the increase of the offset value from $35 \%$ to $37 \%$. The share of cooling losses and friction losses for the assumed offset values is maintained at a comparable level of $11-12 \%$ and $6-7 \%$, respectively. The share of friction losses, exhaust losses and cooling losses decreases slightly for an offset of $10^{\circ}$. For an offset of $20^{\circ}$, the exhaust losses increase, the cooling losses decrease and the friction losses remain unchanged. The share of power consumed by the compressor at an offset of $20^{\circ}$ was slightly smaller, while for an offset of $10^{\circ}$ it increased from $5 \%$ to more than $7.5 \%$, which is an effect of the change in the defined ratio between the crankshaft and the compressor 
shaft. This translates into the decrease in the share of effective power in the overall energy balance from $37.5 \%$ to $35 \%$. The share of other losses including those of blow-by, radiation and heat transfer through connecting pipes constitutes an insignificant part of the energy balance, and ranges from 1.5 to $2.5 \%$.

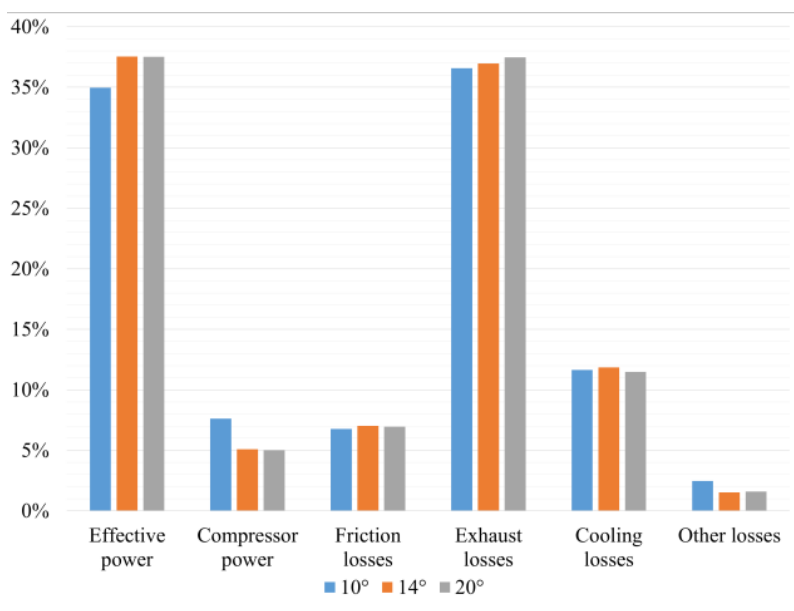

Fig. 6. Percentage shares of the calculated power for different offset values for the continuous maximum power.

Fig. 7 shows the difference in the percentage of the calculated powers according to the offset in relation to a reference value of $O=14^{\circ}$.

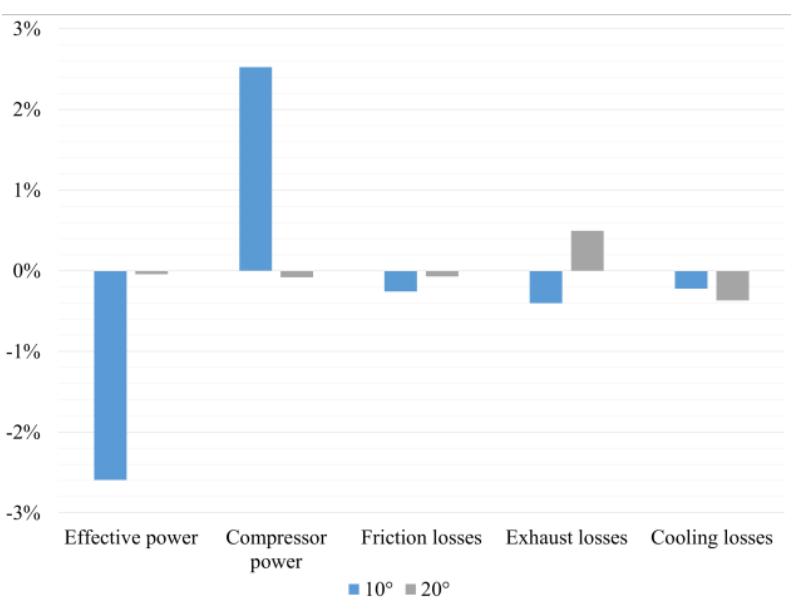

Fig. 7. Difference in the percentage of the calculated power for different offset values for the continuous maximum power.

\section{Conclusions}

In reality, it is difficult to measure individual losses in the internal combustion engine. The simulation method is an alternative which enables quick and low-cost examination of energy losses in any defined operating conditions. This method was used here to perform the energy analysis of the operation of the designed aircraft piston engine.

As a result of the performed simulations, the energy balance of the tested model of a two-stroke opposed piston diesel engine for the defined offset values was obtained.

The largest share of all losses was attributable to the exhaust losses, amounting to over $1 / 3$ of the total energy balance. The cooling losses amounted to approx. 10\%, and the friction losses to approx. $7 \%$ of the total power generated as a result of combustion of an air-fuel mixture.

Decreasing the offset value in relation to the reference results in decreased effective power. In order to compensate for it and obtain models that provide the same effective power, it is necessary to change the ratio between the crankshaft and the compressor. This change results in a significantly increased power consumed by the compressor, which translates into a larger share of energy contained in fuel. In addition, the shares of friction losses, exhaust losses and cooling losses increase.

The increase of the offset value relative to the reference one results in a slight increase in the outlet losses. The power consumed by the compressor, the power of friction losses and the power of the cooling losses are reduced.

This work has been realised in the cooperation with The Construction Office of WSK "PZL-KALISZ" S.A." and is part of Grant Agreement No. POIR.01.02.00-00-0002/15 financed by the Polish National Centre for Research and Development.

\section{References}

1. Z. Czyż, P. Magryta, Eksploat. Niezawodn. 18(4), 507-513 (2016)

2. M. Wendeker, Z. Czyż, Eksploat. Niezawodn. 18(1), 89-97 (2016)

3. Z. Czyż, Ł. Grabowski, K. Pietrykowski, J. Czarnigowski, M. Porzak, Measurement 113, 46-52 (2018)

4. Ł. Grabowski, Z. Czyż, K. Kruszczyński, SAE Technical Paper 2014-01-2883 (2014)

5. K. Siadkowska, M. Wendeker, A. Majczak, G. Baranski, M. Szlachetka, SAE Technical Paper 2014-01-2611 (2014)

6. M. Gẹca, M. Wendeker, G. Litak, J. Vibroeng. 14(2), 582-590 (2012)

7. J. P. Pirault, M. Flint, Opposed piston engines: evolution, use, and future applications, SAE International (2010)

8. M. Schmidt, J. Ind. Ecol. 12(1), 82-94 (2008)

9. S. Singh, A. Garg, A. Gupta, A. Permude, SAE Technical Paper 2013-01-2744 (2013)

10. A. Gharehghani, M. Koochak, M. Mirsalim, T. Yusaf, Appl. Therm. Eng. 60(1-2), 200-207 (2013)

11. O. Durgun, Z. Şahin, Energy Convers. Manag. 50(1), 43-51 (2009)

12. P. N. Shrirao, A. N. Pawar, JMET 3(1), 45-54 (2011)

13. D. S. Gokul Raja, M. Thiyakarajan, IJSRD 4(4), 1091-1094 (2016)

14. A. Uzun, M. Akçil, Surf. Coat. Technol. 116, 505507 (1999)

15. H. Hazar, Renew. Energ. 34(6), 1533-1537 (2009) 
16. I. Taymaz, Energy 31(2-3), 364-371 (2006)

17. D. Zhu, X. Zheng, Energy 141, 702-714 (2017)

18. C. Sprouse III, C. Depcik, Appl. Therm. Eng. 51(12), 711-722 (2013)

19. E. H. Wang, H. G. Zhang, B. Y. Fan, M. G. Ouyang, Y. Zhao, Q. H. Mu, Energy 36(5), 3406-3418 (2011)

20. T. Endo, S. Kawajiri, Y. Kojima, K. Takahashi, T. Baba, S. Ibaraki, T. Takahashi, M. Shinohara, SAE Technical Paper 2007-01-0257 (2007)

21. V. Dolz, R. Novella, A. García, J. Sánchez, Appl. Therm. Eng. 36, 269-278 (2012)

22. F. Yüksel, M. A. Ceviz, Energy 28(11), 1069-1080 (2003)

23. H. Özcan, M. S. Söylemez, Energy Convers. Manag. 47(5), 570-581 (2006)
24. Z. Şahin, O. Durgun, Fuel 86(3), 388-399 (2007)

25. E. A. Ajav, B. Singh, T. K. Bhattacharya, Energy Convers. Manag. 41(14), 1533-1541 (2000)

26. J. Benajes, P. Olmeda, J. Martín, D. Blanco-Cavero, A. Warey, Energy, 122, 168-181 (2017)

27. S. Kim, S. Park, S. Kim, S. H. Rhi, J. Electron. Mater. 40(5), 812-816 (2011)

28. K. Ikoma, M. Munekiyo, K. Furuya, M. A. K. M. Kobayashi, T. A. I. T. Izumi, K. A. S. K. Shinohara, Thermoelectrics, Proceedings ICT 98. XVII International Conference IEEE, 464-467 (1998)

29. J. C. Bass, N. B. Elsner, F. A. Leavitt, AIP Conference Proceedings 316(1), 295-298 (1994)

30. G. Stiesch, Modeling Engine Spray and Combustion Processes, Springer-Verlag Berlin (2003) 